\title{
Dengue em localidade urbana da região sudeste do Brasil: aspectos epidemiológicos*
}

\author{
Dengue in urban locality of Southeastern, Brazil: \\ epidemiological aspects
}

\begin{abstract}
Ricardo J. S. Pontes* *, Antonio Ruffino-Netto***
PONTES, R. J. S. \& RUFFINO-NETTO, A. Dengue em localidade urbana da região sudeste do Brasil: aspectos epidemiológicos. Rev. Saúde Pública, 28: 218-27, 1994. Foram revistos alguns aspectos da epidemiologia do dengue, como parte do estudo de epidemia ocorrida no Município de Ribeirão Preto, Estado de São Paulo, no período de novembro de 1990 a março de 1991. Deu-se ênfase aos fatores envolvidos no risco de ocorrência do dengue hemorrágico/síndrome de choque do dengue. Traçou-se um quadro de referência a respeito do comportamento epidemiológico do dengue através do tempo e em diferentes áreas geográficas. A epidemia de Ribeirão Preto foi situada no contexto da progressão do dengue em nível mundial, nas Américas, e particulamente no Brasil e Estado de São Paulo.
\end{abstract}

Descritores: Dengue, epidemiologia.

No período de novembro de 1990 a março de 1991 ocorreu uma epidemia de dengue em Ribeirão Preto, SP. Em nota prévia anterior ${ }^{32}$ foram descritos alguns aspectos desse processo epidêmico. Opresente trabalho faz parte de estudo mais aprofundado sobre sua evolução ${ }^{33}$, bem como sobre o impacto das medidas de controle executadas pelos serviços de saúde.

\section{Dengue}

\subsection{Etiologia e relação agente - hospedeiro}

A etiologia viral do dengue foi determinada em 1906, quando Ashburn e Craig encotraram um agente infeccioso filtrável em sangue humano. Bancroft descreveu a transmissão do dengue pelo Aedes aegyptiem 1906. Posteriosmente, Siler e col. (1926) e Simmons e col. (1931) conseguiram transmitir a doença em

* Parte da tese de doutorado apresentada ao Departamento de Medicina Social da Faculdade de Medicina de Ribeirão Preto da Univercidade de São Paulo, em dezembro de 1992, intitulada "Estudo da epidemia de dengue no Município de Ribeirão Preto - SP, 1990-1991".

* Departamento de Saúde Comunitária, Setor de Medicina Social. Centro de Ciências da Saúde da Universidade Federal do Ceará - Fortaleza, CE - Brasil.

* * Departamento de Medicina Social da Faculdade de Medicina de Ribeirão Preto da Universidade de São Paulo - Ribeirão Preto, SP - Brasil.

Separatas/Reprints: R. J. S. Pontes - Rua Professor Costa Mendes, 1.608, Rodolfo Teofilo- 60431-970 - Fortaleza, CEBrasil voluntários. Importantes investigaçð̃es realizadas por Sabin e Schlesinger, durante a Segunda Guerra Mundial, resultaram no isolamento dos dois primeiros sorotipos do vírus do dengue, em 1944 -os sorotipos $1 \mathrm{e} 2$. Na década de 50 , Hammon e col. ${ }^{12}$ isolaram mais dois sorotipos (os sorotipos 3 e 4) quandoestudavam a epidemia de dengue hemorrágico ocorrida em Manila (Filipinas), em 1956. Sabe-se hoje que o agente etiológico do dengue é respresentado por um complexo de quatro sorotipos de vírus da família Flaviviridae, gênero Flavivirus, todos causando a mesma síndrome clínica: são eles o Dengue1 (Den-1), Dengue-2 (Den-2), Dengue-3 (Den-3) e Dengue-4 (Den-4). Cada um desses sorotipos possui várias cepas diferentes difundidas na mesma região ou em diversaspartes domundo. Estudosem nívelmolecular e antigênico têm procurado identificar eclassificar cada sorotipo segundo variantes geográficas - topotipos. A importância desses estudos reside na determinação das variaçōes decorrentes de mutações ao longo do tempo, na possibilidade de identificação da origem da cepa envolvida em processos epidêmicos específicos, bem como na tentativa de estabelecer possíveis relações entre a virulência e uma configuração antigênica particular de uma determinada cepa. A infecção pelo vírus do dengue provoca uma proteção imunológica completa contra o mesmo sorotipo, provavelmente pelo resto da vida, ao mesmo tempo em que promove proteção cruzada contraoutros sorotipos durante um breve periodo de tempo, cerca de doze semanas ${ }^{12,14,21,24,38}$.

$O$ dengue manifesta-se como uma enfermidade infecciosa aguda caracterizada por um amplo espectro clínico que varia desde formas de infecção assintomática ou febre indiferenciada, até as graves formas de hemorragia e/ou choque. Os casos típicos do dengue podem ser agrupados em duas categorias principais: 
a) síndrome de febre do dengue ou dengue clássico; b) febre hemorrágica do dengue ou dengue hemorrágico/síndrome de choque do dengue - $\mathrm{DH} /$ $\mathrm{SCD}$. O dengue clássico caracteriza-se por uma febre alta de início abrupto, cefaléia intensa, dor retroorbitária, dores articulares e musculares, prostração, acompanhada algumas vezes de exantema máculopapular, podendo ocorrer alguns fenômenos hemorrágicos sem maiores consequiências (petéquia, epistaxe, gengivorragia). O dengue hemorrágico/ síndrome de choque do dengue é caracterizado por um quadro de febre alta, inicialmente indiferenciável do dengue clássico, que se segue - quando da normalização da temperatura, entre o terceiro e o quinto dia da enfermidade - de fenômenos hemorrágicos ( petéquia, púrpura, equimose, epistaxe, sangramento gengival, sufusões hemorrágicas, hematêmese, melena) e/ou insuficiência circulatória com ou sem choque hipovolêmico. Prova do torniquete positiva, trombocitopenia ( $100.000 / \mathrm{m}^{3}$ ou menos) e hemoconcentração (aumento de $20 \%$ ou mais no hematócrito) são achados característicos do DH/SCD. A organização Mundial da Saúde (OMS) preconiza uma série de critérios clínico/laboratoriais para o diagnóstico do $\mathrm{DH} / \mathrm{SCD}, \mathrm{e}$, tomando por base esses critérios, estabelece diferentes estágios de gravidade que corresponderiam a graus evolutivos da doença - dengue hemorrágico Grau I, II, III e IV 24,40.

A experiência acumulada em mais de três décadas de observação mostra que o $\mathrm{DH} / \mathrm{SCD}$ pode ocorrer em dois grupos principais, assim constituídos ${ }^{1,24,30,34,51}$ :

a. indivíduos primoinfectados, ou seja, apresentando a primera infecção por qualquer um dos quatro sorotipos do vírus do dengue. Neste grupo são acometidas: crianças menores de um ano de idade durante epidemias de DH/SCD; crianças ou adultos, sob a forma de casos isolados e relativamente raros de $\mathrm{DH} /$ $S C D$, durante epidemias de dengue clássico (embora também tenham sido descritas epidemias de DH/SCD em populaçð̃es sem expriência anterior com o vírus do dengue ou em locais onde este vírus esteve ausente por várias décadas);

b. indivíduos com infecção secundária ou seqüencial, ou seja, indivíduo já infectado anteriormente e desenvolvendo nova infecção por um sorotipo do vírus do dengue diferente do anterior. Constitui-se no principal grupo de risco para a ocorrência do $\mathrm{DH} /$ SCD, podendo os casos se apresentarem de modo epidêmico ou endemo-epidêmico. Nestas circunstâncias são acometidas principalmente crianças entre $3 \mathrm{e}$ 7 anos de idade, a maior parte dos casos ocorrendo abaixo dos 16 anos.

Há na literatura uma controvérsia a respeito dos mecanismos patogênicos que determinariam a evolução do dengue na direção da forma clássica ou da síndrome hemorrágica/choque. Duas hipóteses principais procuram explicar o fenômeno.
A primeira hipotese conhecida coma Teoria da Infecção Seqüencial, desenvolvida por Halstead ${ }^{9,10}$, considera que o $\mathrm{DH} / \mathrm{SCD}$ é o resultado de uma resposta imunológica alterada que ocorreria em portadores de experiência imunológica anterior com o dengue, quando submetidos a uma nova infecção por sorotipo diferente daquele ao qual já haviam sido expostos. Ou então, nos menores de um ano de idade com infecção primária, quando gerados por mãe portadora de experiência imunológica com o dengue, transferida por via placentária para o concepto. Nessas situações, a presença de anticorpos heterotípicos em circulação, promoveria a formação de complexos antígeno-anticorpo que, ligando-se aos receptores Fc da membrana celular, facilitariam a penetração e multiplicação viral no interior dos fagócitos mononucleares (fenômeno denominado "antibody-dependent enhacement" - ADE). Comoconsequiência, uma maior quantidade de células daquela linhagem seria infectada e, por um mecanismo ainda não conhecido, haveria a liberação transitória de mediadores químicos responsáveis: pelo aumento da permeabilidade vascular, com a consequiente efusão de plasma para o espaço extra-vascular, resultando no quadro de hipovolemia, hemoconcentração e choque; e por alteraçōes da hemostase, com trombocitopenia, certo grau de vasculopatia, distúrbios da coagulação, e em alguns casos, coagulação intravascular disseminada, resultando nos quadros hemorrágicos. Esses dois fenômenos se constituiriam as bases fisiopatológicas fundamentais do $\mathrm{DH} /$ SCD.

Uma segunda hipótese, cujo principal defensor é Rosen $^{36,37}$ considera que a evolução desfavorável resultaria da infecção por cepas mais virulentas do vírus do dengue. Tais cepas teriam possivelmente se originado em circunstâncias de hiperendemicidade e circulaçãoconcomitante de múltiplos sorotipos virais, de mutações gênicas decorrentes de sucessivas replicações em hospedeiros filogeneticamente tão distintos como o homem e o artrópode vetor (ou mesmo, em reservatórios silvestres residuais, representados por macacos). Outra possibilidade seria a ocorrência de recombinação gênica, resultante de infecçð̃es simultâneas por sorotipos virais diferentes, tanto no hospedeiro humano como no vetor. Segundo esta hipótese, não seria necessária a infecção prévia para desenvolver o $\mathrm{DH} / \mathrm{SCD}$, como mostram os exemplos de casos isolados e epidemias em populações primoinfectadas.

Atualmente existe tendência de se considerar uma visão mais abrangente sobre a patogênese do $\mathrm{DH} / \mathrm{SCD}$ que integra as duas posições anteriormente citadas. Nessa perspectiva, concorreria série de fatores de risco para explicar as formas graves da doença: fatores relativos ao hospedeiro, onde a experiência imunológica teria papel fundamental, principalmente para a ocorrência de epidemias (embora existam outros 
fatores de risco, de caracter individual, envolvidos: idade, sexo feminino, raça branca e doenças crônicas como asma ou diabete); fatores relativos ao agente etiológico, ou seja, a maior ou menor virulência da cepa infectante; fatores relativos ao meio ambiente, principalmente aqueles que favorecessem a presença do vetor em alta densidade ${ }^{17}$.

Outro aspecto relevante da patogênese do dengue é que qualquer um dos quatro sorotipos do vírus pode provocar a forma hemorrágica da enfermidade, embora exista associação mais freqüente, observada no sudeste asiático, nas infecções sequienciais terminadas com o DEN-3 e, principalmente, o DEN-2. Também a seqüência DEN-1/DEN-2 tem-se mostrado particularmente importante para a ocorrência de $\mathrm{DH} / \mathrm{SCD}$, como se observou na Tailândia e na região das Américas em anos mais recentes. As evidências epidemiológicas sugerem que o $\mathrm{DH} / \mathrm{SCD}$ ocorre com maior frequiencia dentro de um intervalo entre 3 meses até 5 anos a partir da infecção primária. Atente-se para o fato de que os casos de DH/SCD correspondem a uma fração do total dos casos de dengue ocorridos em um determinado grupo populacional submetido a infecção secundária, ou seja, a maior parte das pessoas, mesmo apresentando uma infecção seqüencial, evoluirá para os quadros mais benignos do dengue $24,30,40,51$.

As alterações fisiopatológicas do $\mathrm{DH} / \mathrm{SCD}$ são lenômenos transitórios e auto-limitados e que o êxito de seu controle clínico está na dependência da implantação de medidas assistenciais precoces e adequadas ${ }^{24}$.

\section{2 - Cadeia de ransmissão do dengue}

O ciclo de transmissão do dengue inclui o homem doente, qualquer dos quatro sorotipos do vírus do dengue. o mosquito vetor do gênero Aedes e o homem suscetível. A transmissão do dengue ao homem suscetível se dá pela picada de mosquitos do gênero Aedes infectados pelo vírus do dengue. As principais espécies envolvidas são o Aedes aegypti, o Aedes albopictus e as espécies do complexo Aedes scutellaris. O período de incubação do dengue no homem (período de incubação intrínseco) é de 3 a 15 dias, geralmente em torno de 5 a 6 dias. O período de viremia no hospedeiro humano, quando o repasto sangǘneo torna o mosquito infectado, inicia-se um dia antes do aparecimento da febre e permanece até o sexto dia da enfermidade. O período de incubação no mosquito (período de incubação extrínseco) é de 8 a 11 dias, momento a partir do qual ele se torma infectante. assim permanecendo pelo resto da vida ${ }^{2+,+0}$.

\section{Aspectos da biologia e ecologia do vetor do dengue}

A circulação e perpetuação do vírus do dengue na natureza, na estrutura epidemiológica atual, se deve ao hospedeiro humano infectado, e ao vetor da enfermidade, os mosquitos do gênero Aedes, especialmente nos grandes centros urbanos onde a doença se mantém de forma endemo-epidêmica. Rodhain ${ }^{35}$, em recente revisão da literatura, cita os trabalhos de Rudnick e colaboradores na Ásia, e de instituições de pesquisa francesas na África, que sugeririam a existência de ciclo silvestre do dengue entre macacos em florestas tropicais daquelas regiões. Tal reservatório silvestre, entretanto, se existente, não teria nenhuma importância na epidemiologia do dengue nos dias de hoje. É possível que a transmissão vertical transovariana represente outra forma de manutenção do vírus do dengue em algumas situações muito específicas em zonas rurais ou florestas, nos períodos inter-epidêmicos ou de ausência de chuvas ${ }^{14,21}$.

No hemisfério ocidental, a principal espécie envolvida na transmissão do dengue é representada pelo Aedes aegypti.

O Aedes aegypti é provavelmente originário da África, região da Etiópia, acreditando-se que tenha sido introduzido na América em época precoce da colonização, por meio das embarcações provenientes daquele continente. Distribui-se amplamente nas regiơes tropicais e subtropicais do globo terrestre, principalmente entre os paralelos $45^{\circ}$ de latitude norte e $35^{\circ}$ de latitude sul, não se adaptando bem a grandes altitudes. Trata-se de um mosquito de hábitos essencialmente domésticos e dotado de grande antropofilia, embora existam subespécies com alguma afinidade por ambientes silvestres. Seu habitat está intimamente ligado às condições domiciliares ou peridomiciliares a ele ofertadas pelo modo de vida das populações humanas. Sua preferência pelos depósitos artificiais como local de oviposição, faz com que a concentração populacional advinda com a urbanização, ao lado da larga utilização modemaderecipientes artificiais, sejafator determinante na sua crescente proliferação nos centros urbanos das regiões tropicais e subtropicais do planeta. Várias outras características biologicas do Aedes aegypit têm importância na densidade populacional desse vetor. Dentre as principais delas está a influência favorável das temperaturas mais elevadas e das precipilações pluviométricas abundantes. Os ovos constituem-se a principal forma de resistência do Aedes aegypti, podendo permanecer viáveis por cerca de um ano. $O$ período de vida do mosquito adulto é de poucas semanas. podendo chegar entretanto a 45 dias. O tempo tanscorrido entre a eclosão do ovo e a forma adulta. em condições favoráveis varia em tomo de 10 dias ${ }^{3,6}$.

O Aedes albopictus. espécie com ampla distribuição no sul da Ásia oriental e no Pacífico Sul, até há bem pouco tempo não havia se introduzido de forma definitiva no ocidente (embora, em 1946, tenha sido encontrada nos Estados Unidos). Provavelmente percorrendo as grandes rotas do comércio internacional. em 1985 penetrou no Texas e posteriormente em vários outros Estados dos EUA ${ }^{13,26}$. 
No ano de 1986, o Aedes albopictus foi encontrado também no Brasil, simultaneamente no Rio de Janeiro, em Minas Gerais e no Espírito Santo. Acredita-se que a origem desses focos tenha sido o Japão, através do intercâmbio marítimo desse país com o sistema portuário do Estado do Espírito Santo (Companhia Vale do Rio Doce), disseminando-se a partir daí para vários Estados brasileiros 4,18,26. O Aedes albopictus passa a contituir-se, dessa forma, numa nova possibilidade de integrar o elo na cadeia epidemiológica de transmissão do dengue também da região das Américas.

O Aedes albopictus, uma espécie originalmente silvestre, possui capacidade de sobrevivência e multiplicacão em ambientes mais amplos do que aqueles restritos ao domicílio e peridomicílio. Mostra boa adaptação aos criadouros artificiais próprios da convivência humana, chegando mesmo a compartilhar esses locais de procriação com o Aedes aegypti. Mas também é bem adaptado aos ambientes onde predominam os espaços abertos com vegetação, nas áreas urbanas ou suburbanas, e na zona rural. Neste caso, utiliza para oviposição coleções hídricas acumuladas em ocos de árvores, no embricamento de folhas, em orifícios de bambus, entre outros. Na competição entre o Aedes aegypti e o Aedes albopictus, o primeiro prevalece no meio urbano, enquanto que o segundo é favorecido no meio externo das zonas suburbanas e rurais. Essas características de menor antropofilia e de boa adaptação a ambientes naturais dificulta seu controle por meio das técnicas anti-Aedes tradicionalmente utilizadas ${ }^{26}$.

\section{Dengue nas populaçóes humanas}

\subsection{0 dengue a nivel mundial}

As primeiras epidemias de uma doença compatível com o dengue, referidas na literatura, datam de 1779 em Jacarta e no Cairo. No ano seguinte, 1780, surge a primeira descrição clínica dessa enfermidade, feita por Benjamin Rush, durante uma epidemia na Filadélfia. No Século XIX e primeiras decádas do Século XX, foram registradas em diversas partes do mundo várias epidemias atribuídas ao dengue ${ }^{14}$ : Zanzibar (1823; 1870), Calcutá (1824; 1853; 1871; 1905), Antilhas (1827), Hong Kong (1901), Estados Unidos (1922), Austrália (1925-26; 1942), Grécia (1927-28), Japão (1942-45).

A década de 50 é marcada por importante acontecimento na epidemiologia do dengue. É reconhecida e descrita pela primeira vez uma nova e grave entidade clínica associada ao vírus do dengue. Em 1954, Quintos e col. (referidos por Johnson e col. ${ }^{15}$ ) relataram em Luzon (Filipinas) uma doença febril hemorrágica grave em crianças, freqüentemente fatal, que foi chamada febre hemorrágica das Filipinas. Posteriormente, em 1956, outra epidemia dessa febre hemorrágica ocorreu em Manila (Filipinas). Novamente em 1958, volta a ocorrer, agora em Bangkoke proximidades (Tailândia), epidemia semelhante, febre hemorrágica da Tailândia.

Hammon e col. ${ }^{12}$, estudando o problema, estabeleceram sua relação etiológica com o vírus do dengue (tendo isolado dois novos sorotipos, o 3 e o 4). O reconhecimento dessa nova síndrome-denominada febre hemorrágica dodengue ou dengue hemorrágico/ síndrome de choque do dengue/DH/SCD - foi seguida, nos anos subsequientes, por uma progressiva disseminação de casos semelhantes por todo o sudeste asiático e pacífico sul, tanto na forma epidêmica comoendemoepidêmica, vindo a se constituir em um dos principais problemas de saúde da região ${ }^{12,15,33}$.

Apesar do reconhecimento e caracterização clínico-epidemiológica do DH/SCD ter se dado somente a partir da década de 50 , existem evidências da ocorrência anterior de epidemias dessa forma do dengue, em pelo menos quatro ocasiões, referidas por Johnson e col. ${ }^{15}$ : Queensland (Autrália), com 30 óbitos, em 1897; Durban (África do Sul), com 50 mortes entre 50.000 casos, em 1927; Grécia, com 1.250 mortes em 800.000 casos estimados, em 1928; e em crianças de Formosa, em 1931.

Não se sabe bem o motivo pelo qual o DH/SCD comportou-se como enfermidade relativamente rara antes dos anos 50, tornando-se a partir daí uma das principais causas de morbi-mortalidade, principalmente para a população infantil do sudeste asiático e ilhas do Pacífico Sul. Halstead " enfatiza a respeito de que, nos últimos trinta anos, essa forma de dengue tornou-se progressivamente endêmica na maioria dos países da Ásia tropical. Observa também que a incidência da doença vem apresentando um aumento cada vez maior com o passar do tempo, chamando a atenção para o fato de que os casos relatados entre 1980-1989 igualam ou excedem o total de casos observados nos vinte primeiros anos da história do DH/SCD, entre 1961 e 1980. Provavelmente fatores de ordem social, como a intensa urbanização e o maior intercâmbio entre diferentes regiões do planeta,

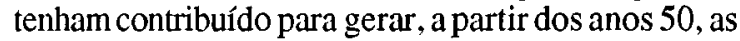
condições ecológicas apropriadas para o aumento da incidência do dengue de uma maneira geral, para a circulação simultânea ou seqüencial de diferentes sorotipos virais em uma mesma área geográfica, possibilitando o aparecimento de grandes contingentes populacionais portadores de experiência imunológica com o dengue e, portanto, sob risco de apresentar sua forma hemorrágica.

Alualmente o dengue acomete a cada ano milhares de pessoas nas regiōes tropicais e subtropicais da Ásia, Africa, Américas, Austrália e Oceania. Tem-se observado que novas regiões e diversos países, antes não atingidos, vêm apresentando atividade epidêmica, 
com a circulação simultânea ou sucessiva de vários sorotipos virais, indicando crescente disseminação do dengue no mundo ${ }^{11}$.

\subsection{Dengue nas Américas}

Nas Américas, o dengue como entidade clínica é conhecidohápelosmenos 200 anos. Aprimeirapandemia registrada na região, tomando como referência critérios clínicos e epidemiológicos, ocorreu nas Antilhas-Golfo do México-Atlântico, em 1827-28. A partir daí, até a década de 1950 , várias outras se sucederam na mesma área, intercaladas por longosanos desilêncio: pandemias de $1850-51,1879-80,1897-99,1905-07,1922,1934-$ 38, 1941-46. Depois da década de 50 até os dias atuais, observou-se intensificação da atividade do dengue no continente americano, verificando-se intervalos mais curtos entre os períodos pandêmicos, e o envolvimento de novas áreas geográficas anteriormente não atingidas, como a América do Sul: são momentos de grande atividade epidêmica nesse espaço de tempo, por exemplo, os anos de 1963-64, 1968-69, 1977-80, 1981-82, $1986-91^{2,27,31}$.

O advento de técnicas laboratoriais de identificação, a partir da década de 50, possibilitou a realização de estudos a respeito da circulação dos diversos sorotipos do virus do dengue nessa área. Assim, nas Antilhas, foi identificado o sorotipo $2 \mathrm{em}$ Trinidad (1952). Estudos sorológicos retrospectivos mostraram que houve circulação desse sorotipo no Panamá em 1941-42. Na década de 60, isolou-se o sorotipo 3 em Porto Rico (1964-65). Até a década de 70 apenas esses dois sorotipos tinham circulado na região ${ }^{31}$.

O sorotipo 1 foi introduzido em 1977 na Jamaica, quando ocorreu pandemia de importantes proporções em vários países das Antilhas, com grande número de casos e extensa área geográfica envolvida ${ }^{29}$. O sorotipo 4 foi identificado pela primeira vez em 1981, causando epidemias nas Antilhas, América Central continental, México e norte da América do Sul ${ }^{25}$. Nos últimos anos tem-se observado a presença apenas dos sorotipos 1, 2 e 4 nas diversas epidemias ocorridas nos países do continente americano ${ }^{27}$.

$\mathrm{O}$ aspecto mais relevante da epidemiologia do dengue nas Américas, nos anos mais recentes, foi a ocorrência do primeiro processo epidêmico de $\mathrm{DH} /$ SCD na região, em Cuba, no ano de 1981. Cuba estivera livre do dengue desde 1945 até 1977 . quando foi atingida pela pandemia que ocorreu nas Antilhas, a partir da introdução do sorotipo 1 naquela área. Foram registrados em Cuba, na ocasião, perto de meio milhão de casos de dengue clássico, sendo que um inquérito sorológico realizado em 1978 mostrou que $44,5 \%$ da população cubana dos centros urbanos havia sido infectada pelo vírus sorotipo 1. Em 1981, nova epidemia de dengue ocorreu, agora causada pelo sorotipo 2, e com o aparecimento massivo de casos de
DH/SCD. No período de aproximadamente 3 meses foram notificados 344.203 casos de dengue, com 116.151 hospitalizaçð̃es, 24.000 casos classificados como DH/SCD (desses, 10.312 casos graves, Grau III e IV, segundo os critérios da OMS) e 158 obitos (101 crianças e 57 adultos) ${ }^{16,24}$.

Chama a atenção o fato de que antes da epidemia de $\mathrm{DH} / \mathrm{SCD}$ em Cuba somente haviam sido esporadicamente referidos casos isolados dessa enfermidade em Curaçao (1968), Porto Rico (1975), Jamaica (1977) e Honduras (1978). Na década de 1980, indicando uma importante mudança no compertamento epidemiológico do dengue na região, anualmente passaram a se registrar casos de $\mathrm{DH} /$ SCD em número crescente de países (nove países até 1989) ${ }^{27,31}$. Finalmente foram observadas epidemias de DH/SCD na Venezuela em 1989-90 52, e no Brasil, em 1990-91 ${ }^{\text {s0. }}$.

$\mathrm{O}$ aparecimento de epidemias de $\mathrm{DH} / \mathrm{SCD}$ nas Américas sugere que o dengue esteja evoluindo nesse continente tal como o fez na região asiática a partir da década de 50. De fato, observa-se no Continente Americanoa circulação simultânea de vários sorotipos virais, a ocorrência endemo-epidêmica do dengue clássico em um número crescente de países, a intensificação da infestação por Aedes aegypti nos centros urbanos, o surgimento das primeiras epidemias de DH/SCD, circunstâncias também verificadas nos países do sudeste asiático nos anos 50.

\subsection{Dengue no Brasil}

Os primeiros casos de dengue no Brasil foram relatados, baseados em critérios clínicos, em Niterói, Rio de Janeiro, em 1923. Dessa época até o início da década de 1980 não se observaram novas ocorrências da doença em nosso meio. Somente a partir de novembro de 1981 até o mês de março de 1982 , ocorreu uma epidemia na cidade de BoaVista, Território de Roraima ( na região norte da Amazônia Brasileira), com circulação dos sorotipos 1 e $4{ }^{28}$. Provavelmente tratava-se da expansão da onda epidêmica que atingiu vários países da América Central e do norte da América do Sul nos finais da década de 70 . O relativo isolamento geográfico-econômico da cidade, ao que tudo indica, concorreu para circunscrever a epidemia ao local, já que não se verificou a disseminação do processo epidêmico para outras regiōes do país. Também não existem relatos de sua endemização naquela área, parecendo ter sido um problema limitado àquele momento.

No ano de 1986, nova epidemia de dengue volta a ocorrer no Brasil, agora numa região de grande concentração populacional, com graves problemas de infraestrutura urbana, densamente povoada e localizada no eixo(regiãosudeste)de maior concentraçãode atividades 
econômicas e de fluxo populacional (tanto migratório como turístico) do país, a região metropolitana do Rio de Janeiro e municípios vizinhos. Iniciada em abril de 1986, somente apresentou redução importante dos níveis de incidência a partir de julho-agosto de 1987. tendo sido isolado o sorotipo $1^{22,39}$.

A partir daí ocorreu a disseminação do mesmo sorotipo viral para outros Estados do País, com o estabelecimento de focos autóctones em Alagoas (julho de 1986) e Ceará (setembro de 1986). No ano de 1987, mais quatro Estados foram atingidos: Pernambuco, Bahia, Minas Gerais e São Paulo. Em 1990 o dengue chega ao Mato Grosso do Sul e atinge novamente com grande intensidade o Estado de São Paulo; em 1991 é introduzido no Estado do Tocantins e. em 1992, no Mato Grosso. Pode-se considerar, tomando como referência as séries históricas de dados de notificação para o período 1980-1991, divulgados pelo Ministério da Saúde, que o dengue tomou-se endemo-epidêmico na maioria dos Estados do Brasil onde houve sua introdução ${ }^{19}$.

Merece referência especial nessa sequiência de eventos, pelo seu significado epidemilógico, o isolamento em 1990, pela primeira vez no Brasil, do sorotipo 2 do dengue, no Estado do Rio de Janeiro. A introdução desse sorotipo provocou a primeira epidemia de dengue hemorrágico no país, no mesmo Estado. em 1990-91 23,50. Além do Rio de Janeiro, também se verificou a circulação do sorotipo 2 nos Estados do Tocantins e Alagoas*.

\subsection{Dengue no Estado de São Paulo}

No Estado de São Paulo, de acordo com dados do Centro de Vigilância Epidemiológica da Secretaria de Saúde**. os primeiros casos confirmados de dengue aconteceram em 1986, num total de 32, todos importados (28 do Rio de Janeiro, 2 do Ceará e 2 de Alagoas). No ano de 1987 verificou-se a primeira epidemia no território paulista, em Guararapes (30 casos notificados) e em Araçatuba (16 casos notificados), rapidamente controlada. Nesse mesmo ano foram identificados 265 casos importados procedentes do Rio de Janeiro (e mais 9 de Alagoas e 2 do Ceará), o que sugere ter sido provavelmente o Município do Rio de Janeiro a origem do foco epidêmico da região oeste paulista. Nos anos de 1988 (10 casos), 1989 (10 casos) e 1990 até novembro (com 13 casos) houve confirmação apenas de casos importados. A partir do final de novembro de 1990 e primeiros meses de 1991 ocorreu epidemia de importante magnitude que, irradiando-se de Ribeirão Preto ${ }^{32,33}$ - coincidentemente

\footnotetext{
* Comunicação pessoal (CENEPI - FNS - MS).

*: Comunicação pessoal (SUDS-8- Grupo de Vigilância Epidemológica).
}

localizada numa região próxima ao Mato Grosso do Sul, onde estava ocorrendo também epidemia de dengue - atingiu diversas cidades do interior paulista. Em todas as situações relatadas foi identificada apenas a circulação do vírus sorotipo 1 .

\section{Estratégia de controle do dengue}

A única medida disponível alualmente para a interrupção da cadeia de transmissão do dengue é o combate ao vetor da enfermidade. As vacinas em estudo ainda se encontram em fase experimental; além do que, por não se ter desenvolvido um imunizante tetravalente (contra o DEN-1,2, 3 e 4, simultaneamente), poderiam concorrer como mais um fator de risco para o aparecimento de $\mathrm{DH} / \mathrm{SCD}$, pela sensibilização imunológica apenas contra alguns sorotipos específicos ${ }^{2+}$.

As ações de combate aos Aedes aegypti, na região das Américas, tiveram suas origens nos trabalhos pioneiros de Finlay, depois comprovados por Reed (realizados em Cuba no final do Século XIX e início do Século XX), que estabeleceram, através de confirmações empíricas, o papel desse vetor na transmissão da febre amarela. Gorgas, em 1901, executou a primeira campanha de sucesso contra a febre amarela baseada no combate ao mosquito, na cidade de Havana. Posteriormente, outras campanhas semelhantes realizadas no Panamá, Santos, Rio de Janeiro e Vera Cruz, para cilar alguns exemplos, foram acompanhadas de resultados semelhantes. consolidando a crença na possibilidade de erradicação da febre amarela $a^{5,47}$.

A estratégia de controle desse período baseava-se na suposição de que a redução da infestação do vetor nos grandes centros urbanos onde a febre amarela era endêmica, resultaria no desaparecimento da doença, primeiro nesses locais, para logo em seguida desaparecer também das pequenas cidades e zonas rurais interligadas a esse foco gerador de casos. A experiência dos vários países que desenvolviam ações de combate ao Aedes aegypti, centradas nessa estratégia, levou gradativamente à sua revisão, e à conviç̧ão de que somente com a erradicação completa do vetor em todas as localidades seria possível acabar de vez com a enfermidade. Nesse particular, foram de grande importância as ações desenvolvidas no Brasil através do trabalho cooperativo entre o governo brasileiro e a Fundação Rockefeller, representando uma das principais experiências no acúmulo de conhecimentos dirigidos à luta contra a febre amarela e o Aedes aegypti ${ }^{5,47}$.

A estratégia de erradicação continental do Aedes aegypti foi apresentada pelo governo brasileiro, em 1947, ao Conselho Diretor da Organização Panamericana de Saúde (OPS), como a única maneira de se atingir resultado permanente nesse tipo de 
atividade, já que o sucesso em um país isoladamente não resistiria à pressão de reinfestação proveniente das regiões circunvizinhas. Aprovada, a proposta passou, a partir de então, a constituir-se em política continental coordenada pela OPS e desenvolvida pelos países membros. Como resultado, nas décadas seguintes até os anos 60, verificou-se que um total de 18 países atigiram aquele objetivo proposto (somente não houve a erradicação na Venezuela, ilhas das Antilhas e Sul dos Estados Unidos). O Brasil conseguiu a erradicação em 1955, referendada oficialmente pela OPS em 1958. Atualmente, devido à política de países do continente de não executarem programas de erradicação, como os Estados Unidos, ao lado da falta de continuidade de ações permanentes nesse sentido, por parte daqueles que lograram um êxito inicial, todos aqueles 18 países mencionados se encontram novamente reinfestados $5,11,47,48$.

A tendência atual, dada as dificuldades para uma política continental erradicacionista, ao lado da polêmica sobre a viabilidade ecológica e econômica de tal empreendimento nas condições e características da vida urbana moderna, caminha mais no sentido do controle dos vetores do dengue, através da redução dos níveis de infestação para patamares muito baixos ${ }^{7,8}$.

Problema importante na estratégia de convivência com o Aedes reside na dificuldade de estabelecer qual o limiar de infestação abaixo do qual não ocorreria a transmissão do dengue, pelo menos em patamares epidêmicos. A experiência com o controle da febre amarela fixou como limiar de segurança, para a não-ocorrência de epidemias, infestação vetorial da ordem de até $5 \%$ de casas, embora esse risco dependesse do tipo de população envolvida no que se refere à experiência imunológica anterior com a doença ${ }^{46,49}$. Por analogia, esse limite de segurança também passou a servir de referência para 0 dengue em alguns programas de controle. Entretanto, tem-se observado que mesmo com índices de infestação muito baixos, ainda assim são verificadas epidemias dessa enfermidade. Por exemplo, em Singapura, com Índice de Infestação Predial, de 3\%, ocorreu uma epidemia de 384 casos de DH/SCD, em 1978. Esse Índice foi reduzidopara valores entre 1 e $2 \%$ e novas epidemias aconteceram em $1986,1987,1989$, esta última com 616 casos de DH/SCD, em 15 focos diferentes de transmissão ${ }^{53}$.

Gubler $^{7,8}$ tem proposto, diante das dificuldades encontradas na luta anti-Aedes, a ultilização de um sistema de vigilância ativa do dengue com o objetivo de detectar precocemente a ocorrência de epidemias. Isto possibilitaria pôr em prática medidas de controle imediatas com o objetivo de reduzir a incidência e, desta forma, o risco de ocorrência do dengue hemonágico. Essa vigilância ativa estaria centrada principalmente na organização de um sistema de vigilância virológica, epidemiológica, clínica, sorológica e entomológica. Ao mesmo tempo, o citado autor preconiza a inversão da estratégia de controle, substituindo as campanhas "de cima para baixo" por outras organizadas "de baixo para cima", com ações desenvolvidas a partir da participação e educação comunitária, voltadas para a eliminação de criadouros do vetor.

\section{A reinfestaçáo no Brasll e no Estado de Sáo Paulo}

As primeiras reinfestações pelo Aedes aegypti verificadas no Brasil,depois dealcançadaaerradicação, ocorreram em Belém (Pará) em 1967, e em São Luiz (Maranhão) em 1968, tendo sido eliminados os respectivos focos em 1973. No ano de 1976 constatou-se a presença daquele vetor em Salvador (Bahia) e em 1977 no Rio de Janeiro (Rio de Janeiro). A partir daí houve dispersão para vários outros Estados, ao mesmo tempo que novos focos foram encontrados em áreas interligadas aos países que se limitam com o Brasil. Nesta progressão, em 1980 eram 42 os municípios infestados pelo Aedes aegypti. Em 1990, já existiam registros de 481 municípios infestados por esse mesmo vetor, 349 pelo Aedes albopictus (introduzido em 1986) e 100 por ambos ${ }^{18}$.

No Estado de SãoPaulo ${ }^{42,43,44,45}$, foram encontrados focos de reinfestação pelo Aedes aegypti pela primeira vez em 1980 e 1981, na zona do Porto de Santos, eliminados no mesmo ano. Em 1985, diante da grande dispersão daquele vetor em várias áreas do Brasil, realizou-se levantamento larvário no Estado, encontrando-se $12(2,1 \%)$ municípios com focos, e desses, 9 com infestação domiciliar.

Instituiu-se então, como conseqüência desse quadro, o "Programa de Controle dos Vetores do Dengue a da Febre Amarela no Estado de São Paulo", sob a responsabilidade da SUCEN, iniciado a partir de 1985 (até então o combate ao Aedes era desenvolvido pela Superintendência de Campanhas de Saúde Pública - SUCAM, órgão do Ministério da Saúde). Esse progama objetivava, essencialmente, acompanhar os índices de infestação vetorial de modo a detectar situações de risco para ocorrência de processos epidêmicos, atuando precocemente para evitálas, bem como impedir a dispersão dos vetores do dengue para municípios não infestados. Não incluía, portanto, a erradicação como um objetivo a ser alcançado. Desde 1988 a política de controle de vetores no Estado passou a consistir na municipalização de parte das ações do programa, especialmente as atividades de eliminação de criadouros em nível domiciliar. Nessa estratégia de municipalização, caberia à SUCEN a supervisão e treinamento técnico, a vigilância entomológica através do monitoramento da infestação vetorial destinada à avaliação de riscos epidêmicos, e a execução das ações de maior especialização ou custo operacional, como a pulverização ambiental de inseticidas.

Apesar das atividades de controle desenvolvidas, 


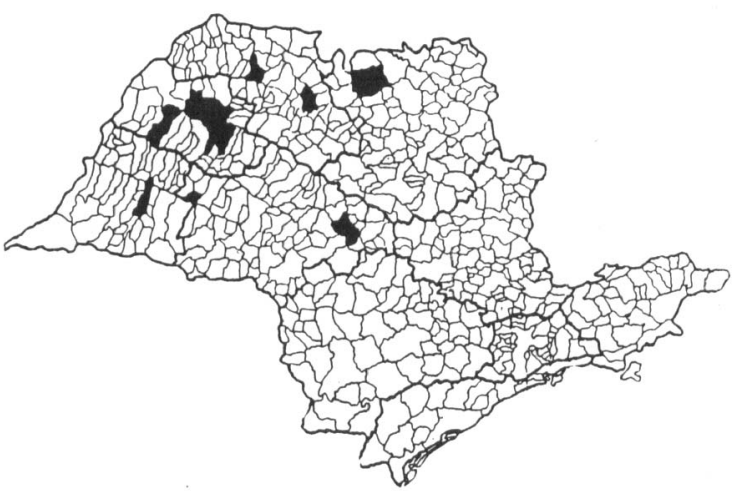

Figura 1 - Intestaçào domicllar por Aedes aegypt por Município, Estado de São Paulo, 1985.

Superintendência de Controle de Endemias (SUCEN) ${ }^{42}$ (1991). Reprodução autorizada

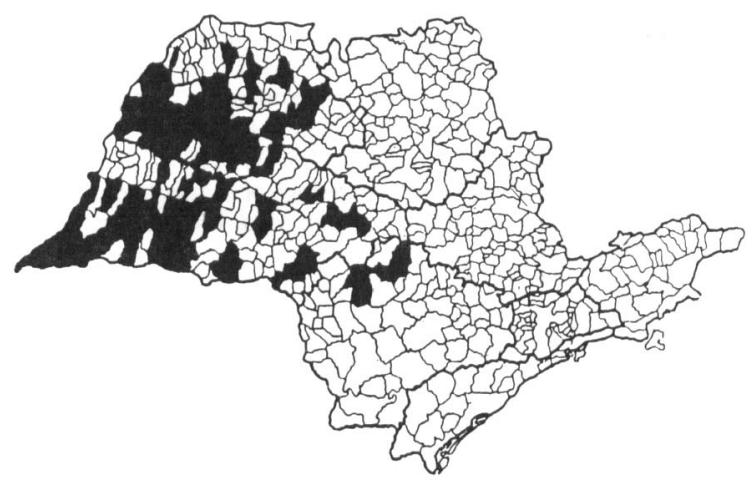

Figura 2 Intestaçào domicllar por Aedes aegypti por Município, Estado de São Paulo, 1986.

Superintendência de Controle de Endemias (SUCEN) ${ }^{42}$ (1991). Reprodução autorizada.

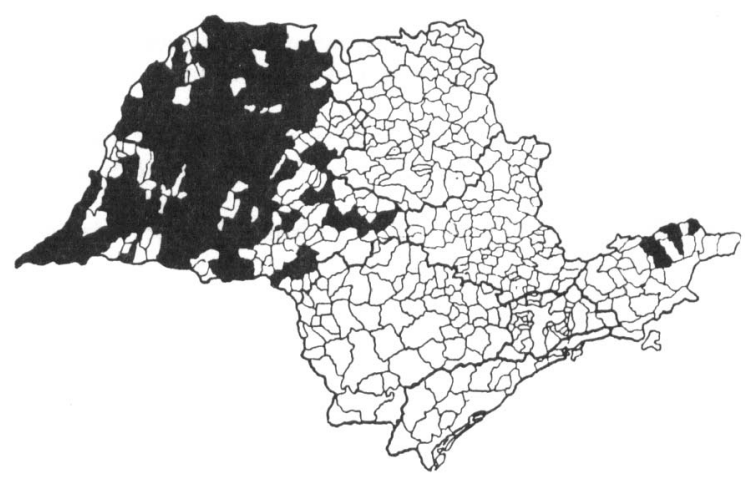

Figura 3 - Intestação domıciliar por Aedes aegyptı e Aedes albopictus por Município, Estado de São Paulo, 1987.

Superintendência de Controle de Endemias (SUCEN) ${ }^{42}$ (1991). Reprodução autorizada.

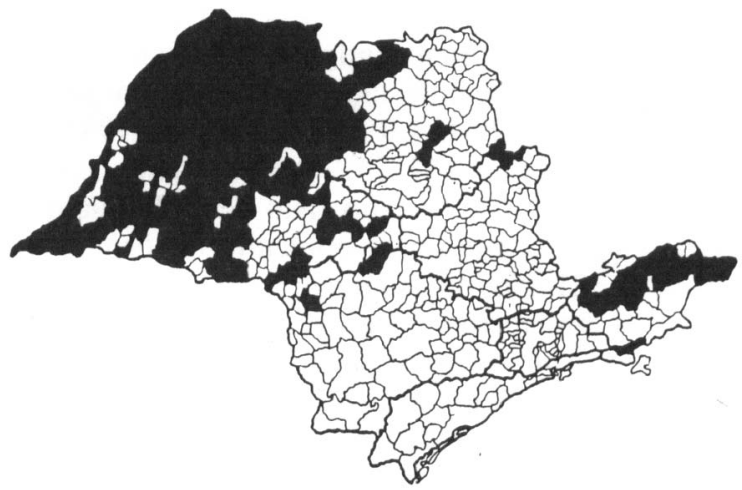

Figura 4 intestaçao domiciliar por Aedes aegyoti e Aedes albopictus por Municípı, Estado de São Paulo, 1988. Superintendência de Controle de Endemias (SUCEN) ${ }^{42}$ (1991). Reprodução autorizada.

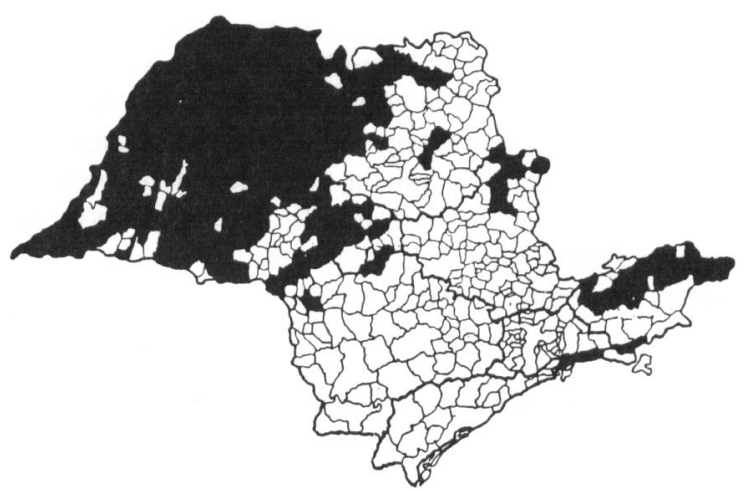

Figura 5 - Infestação domıcliar por Aedes aegyptı e Aedes albopictus por Município, Estado de São Paulo, 1989.

Superintendência de Controle de Endemias (SUCEN) ${ }^{42}$ (1991). Reprodução autorizada.

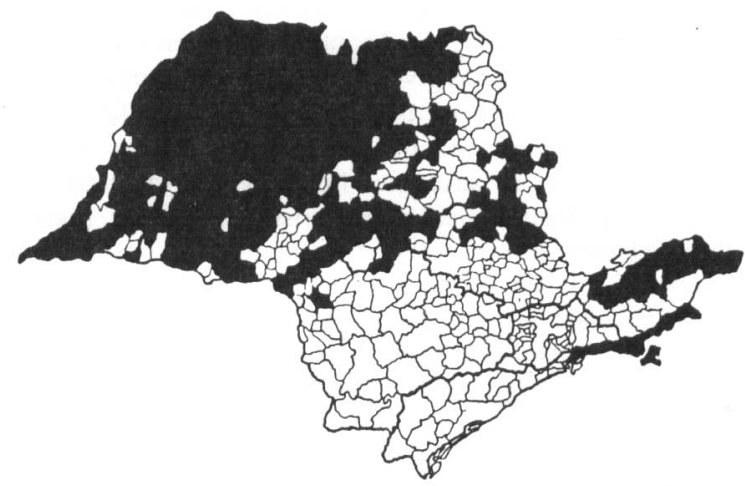

Figura 6 Infestaçào domiciliar por Aedes aegyptı Aedes albopictus por Município, Estado de São Paulo, 1990. Superintendência de Controle de Endemias (SUCEN) ${ }^{42}$ (1991). Reprodução autorizada. 
os levantamentos realizados pela SUCEN, em anos sucessivos, mostraram contínuo aumento no número de municípios com infestação domiciliar: em janeiro de 1987 já havia 85 (14,9\%); em janeiro de 1988 este número subiu para $147(25,7 \%)$; em janeiro de 1989 eram $200(35,0 \%)^{41}$; e no final de 1990/início de 1991, quando ocorreu a epidemia de dengue no Estado, $321(56,1 \%)$ municípios estavam infestados*. A progressão geográfica da infestação pelo Aedes aegypti ocorreu na direção dos municípios situados no oeste para aqueles do leste. Em 1986 foi detectada a presença também do Aedes albopictus no Estado de São Paulo, no Vale do Paraíba, provavelmente originário do Rio de Janeiro, e posteriormente no Município de Ribeirão Preto e municípios da Região de Campinas. Este vetor caminhou na direção de leste para oeste. As Figuras 1 a 6, reproduzidas da SUCEN ${ }^{42}$, ilustram o insucesso das açðes de controle em barrar a expansão dos vetores do dengue no Estado de São Paulo.

Pode-se concluir que a expansão da infestação vetorial em São Paulo, simultaneamente à circulação do vírus do dengue em várias áreas do Brasil, há muito anunciavam a ocorrência de epidemias de maior magnitude no território paulista, como de fato ocorreu em 1990-91, em Ribeirão Preto, de onde se irradiou para outros municípios do Estado,constituindo-se estudo desta epidemia o objeto de publicações posteriores.

\section{Agradecimento}

Á SUCEN pela permissão concedida para reprodução dos Mapas (Figs. 1 a 6).

PONTES, R. J. S. \& RUFFINO-NETTO, A. [Dengue in an urban locality of Southeastern, Brazil: epidemiological aspects]. Rev. Saúde Pública, 28: 218-27, 1994. A dengue fever epidemic which occurred in Ribeirão Preto County, S. Paulo State, Brazil, during the period November, 1990 to March,1991 has been analysed elsewhere. The general aspcts of dengue epidemiology and control have been reviewed in this article. Emphasis is given to the analysis of some factors involved in the risk of dengue haemorrhagic fever and ecological aspects of the vector, as well as to the appropriateness of strategies for dengue erradication or control. Epidemiological characteristics of dengue, mainly those related to its occurrence in different geographical areas and periods of time are described. The RibeirãoPreto epidemic has thus, been set within the context of the spread of the disease at global level, in the Americas, and particularly in Brazil and S. Paulo State.

Keywords: Dengue, epidemiology.

* Comunicação pessoal (Serviço Regional da SUCEN/ R. Preto).

\section{Referências Bibliográflcas}

1. BARNES, W.J.A. \& ROSEN, L. Fatal hemorrhagic disease and shock associated with primary dengue infection on a Pacific Island Am. J. Trop. Med. Hyg., 23: 495-506, 1974.

2. EHRENKRANZ, N.J.et al. Pandemic dengue in Caribbean countries and the Southern United States. Past, Present, and Potential Problems. N. Engl. J. Med. , 285: 1460-9, 1971.

3. FORATTINI, O.P. Entomologia médica. São Paulo, Editora da Universidade de São Paulo, 1965.

4. FORATTINI, O.P. Aedes (Stegomyia) albopictus (Skuse) indentification in Brazil. Rev.Saúde Pública, 20:244-5, 1986.

5. FRANCO, O. História da febre amarela no Brasil. Rio de Janeiro, Ministério da Saúde, Superintendência de Campanhas de Saúde Pública, 1976.

6. GADELHA, D.P. \& TODA, A.T. Biologica e comportamento do Aedes Aegypti. Rev.Bras.Malariol. Doenças Trop. , 37: 29-36, 1985.

7. GUBLER, D.J. Aedes aegypti and Aedes aegyptiborne disease control in the 1990s: top down or botton up. Am. J. Trop. MedHyg., 40: 571-8, 1985.

8. GUBLER, D.J. Vigilância activa del dengue y de la fiebre hemorragica del dengue. Bol. Oficina Sanit. Panam., 107: 22-30, 1989.

9. HALSTEAD, S.B. Pathogenesis of dengue: challenges to molecular biology. Science, 239: (4839): 476-81, 1988.

10.HALSTEAD, S.B. Antibory, macrophages, dengue virus infection, shock, and hamorrhage: a pathogenetic cascade. Rev. Infect. Dis., 11(Suppl.4): S830-9, 1989.

11. HALSTEAD, S.P. Global epideniology of dengue hemorrhagic fever. Southeast Asian J. Trop. Med. Public Health, 21: 636-41, 1990.

12. HAMMON, W. McD. et al. Viruses associated with epidemic hemorthagic fevers of the Philippines and Thailand. Science, 131(3407): 1102-3, 1960.

13. HAWLEY, W.A. et al. Aedes albopictus in North America: probable introduction in tires from Northem Asia. Science, 236(4805): 1114-6, 1987.

14. HENCHAL, E.A. \& PUTNAK, J.R. The dengue viruses. Clin. Microbiol. Rev. , 3: 376-96, 1990.

15. JOHNSON, K.M. et al. Hemorrhagic fevers of Southeast Asia and South America: a comparative appraisal. Prog. Med. Virol. , 9: 105-58, 1967.

16. KOURI, G. et al. Dengue hemorrágico en Cuba: cronica de una epidemia. Bol. Oficina Sanit. Panam., 100: 322-9, 1986.

17. KOURI, G.P. et al. Why dengue haemorthagic fever in Cuba? II An integral analysis. Trans. R. Soc. Trop.Med. Hyg., 81: 821-3, 1987.

18. MINISTÉRIODA SAUUDE. Relatório final de Reunião Técnica do Programa de Combate à Febre Amarela e Dengue. Brasilia, 1991.

19. MINISTÉRIO DA SAÚDE. Séries históricas de agravos e doenças transmissíveis. Inf.Epidemiol. SUS, 1: 25, 1992.

20. MINISTÉRIO DA SAÚDE. Combate aos vetores da febre amarela e do dengue, Aedes aegypti/Aedes albopictus: instruções para gıardas, gutardas-chefes e inspetores. Brasília, 1987.

21. MONATH, T.P. Flavivinuses. In: Fields, B.N. et al.Virology.2nd ed. New York, Raven Press, 1990, v. 1, p. 763-814.

22. NOGUEIRA, R.M.R. et al. Virological study of a dengue type 1 epidemic at Rio de Janeiro. Mem.Inst. Oswaldo Cruz.83: 219-25, 1988.

23. NOGUEIRA, R.M.R. et al. Isolation of dengue virus type 2 in Rio de Janeiro. Mem. Inst. Oswaldo Cruz, 85: 253, 1990.

24.ORGANIZAÇĀO MUNDIAL DA SAÚDE. Dengue hemorrático: diagnóstico, tratamento e controle. Genebra, 1987. 
25. ORGANIZACIÓN PANAMERICANA DE LA SALUD. EI dengue 4 en las Américas. Bol. Epidemiol. , 3(5) 1982.

26. ORGANIZACIÓN PANAMERICANA DE LA SALUD. Ecologia, biologia y control del Aedes albopictus (Skuse).Washington, 1987. [Documento de Trabalho da 99a. Reunião do Comite executivo da OPS].

27. ORGANIZACIÓN PANAMERICANA DE LA SALUD. El dengue y la fiebre hemorrágica de dengue en las Américas: una vision general del problema. BolEpidemiol., 13(1) 1992.

28. OSANAI, C.H. A epidemia de dengue em Boa Vista, Território Federal de Roraima, 1981-1982. Rio de Janeiro, 1984. [Dissertação de Mestrado-Escola Nacional de Saúde Pública].

29. PAHO WORKING GROUP ON DENGUE IN THE CARIBEAN. Montego Bay, 1978. Proceedings. Washington, D.C., Pan American Health Organization, 1979.(PAHOScientific Publication, 375).

30. PANG, T. Dengue haemorrhagic: Virus or host response. Bioessays, 6: 141-4, 1987.

31. PINHEIROS, F.P. Dengue in the Americas: 1980-1987. Epidemiol. Bull., 10: 1-8, 1989.

32. PONTES, R.J.S. et al. Epidemia de dengue em Ribeirāo Preto, SP, Brasil: nota prévia. Rev. Saúde Pública, 25: 315-7, 1991.

33. PONTES, R.J.S. Estudo da epidemia de dengue no município de Ribeirão Preto- SP, 1990-1991. São Paulo, 1992. [Tese de Doutorado - Faculdade de Medicina de RibeirãoPreto da USP].

34. REED, D. et al. Type 1 dengue with hemorrhagic disease in Fiji: epidemiologic fidings. Am.J.Trop.Med.Hyg., 26: 784-91, 1977.

35. RODHAIN, F. The role of monkeys in the biology of dengue and yellow fever.Comp.Immunol.Microbiol.Infect.Dis.14: 9-19, 1991.

36. ROSEN, L. La pathogenese de la dengue hemorragique: discussion critique des hypotheses actuelles. Bull. Soc. Pathol. Exot. Filiales, 79: 342-9, 1986.

37. ROSEN, L. Disease exarcerbation caused by sequencial dengue infections: myth or reality. Rev.Infect.Dis., 11(Suppl.4):S 840-2, 1989.

38. SABIN, A.B. Reasearch on dengue during world war II. Am.J. Trop. Med.Hyg., 1: 30-50, 1952.

39. SCHATZMAYR, H.G. et al. An oubreak of dengue vinus at Rio de Janeiro. Mem. Inst. Oswaldo Cruz., 81: 245-6, 1986.
40. SECRETARIA DE ESTADO DA SAÚDE DE SÃO PAULO. Centro de Vigilância Epidemiológica. Mantual de vigilância epidemiológica: dengue. São Paulo. 1987.

41. SECRETARIA DE ESTADO DA SAÚDE DE SÃO PAULO. Superintendência de Controle de Endemias. Plano emergencial de controle do Aedes aegypti para o verão de 1989. São Paulo, sd.

42. SECRETARIA DE ESTADO DA SAÚDE DE SÃO PAULO. Superintendência de Controle de Endemias. Programas de controle de vetores; relatório técnico. São Paulo, 1991.

43. SECRETARIA DE ESTADO DA SAÚDE DE SÃO PAULO; Superintendência de Controle de Endemias. Proposta de descentralizaçãodo controle de endemias. SãoPaulo, 1991.

44. SECRETARIA DE ESTADO DA SAÚDE DE SÃO PAULO. Superintendência de Controle de Endemias. Vigilância epidemiológica do dengue no Estado de São Paulo, 1991.

45. SECRETARIA DE ESTADO DA SAÚDE DE SÃO PAULO. Superintendência de Controle de Endemias. Plano emergencial para o controle dos vetores do dengue e da febre amarela no verão de 1991-1992, 1991.

46. SMITH, H.H. Controlling yellow fever. In:Strode, G.K. Yellow fever. New York, McGraw-Hill, 1951. p. 539-628.

47. SOPER, F.L. The elimination of urban yellow in the Americas through the eradication of Aedes aegypti. Am. J. Public Health, 53: 7-16, 1963.

48.TAUIL, P.L. Oproblema do Aedes aegypti noBrasil [Editorial]. Rev. Soc. Bras. Med. Trop., 19: 1-3-, 1986.

49. TAYLOR, R.M. Epidemiology. In: Strode G.K. Yellow fever. New York, McGraw Hill, 1951, 427-538.

50. THEME FILHA, M. et al. O dengue no Munícipio do Rio de Janeiro-1990-1991: o dengue hemorrágico. In: Congresso Brasileiro de Epidemiologia, 22, 1992. Anais.

51.WHO EXPERT COMMITTEE ON VIRAL HAEMORRHAGIC FEVERS. Geneva, 1984. Report. Geneva, World Health Organization, 1985. (WHO - Technical Report Series, 721).

52. WORLD HEALTH ORGANIZATION. Dengue hemorthagic fever in Venezuela. Epidemiol. Bull., 11: 7-9, 1990.

53. WORLD HEALTH ORGANIZATION. Epidemiology of dengue fever dengue haemorrhagic fever. Wkly Epidemiol. Rec., 65(14): 104-6, 1990.

Recebibo para publicação em 2.6.1993 Reapresentado em 112.1994 Aprovado para publicação em 7.3.1994 